[Agr. Biol. Chem., Vol. 28, No. 2, p. 105 113, 1964]

\title{
A New Synthetic Method of Methyl Ketones
}

\section{Part II. Acidic Cleavage and Ozonolysis Followed by Alkaline Cleavage of Alkyl Mesityl Oxide}

\author{
By Masanao Matsui and Toshio Yoshid** \\ Department of Agricultural Chemistry, Faculty of Agriculture, \\ The University of Tokyo, Tokyo \\ Received October 16, 1963
}

\begin{abstract}
Alkyl mesityl oxides can be converted to methyl alkyl ketones such as methyl heptanone and hexahydropseudoionone by means of the two different methods, i.e., acidic cleavage and ozonolysis followed by alkaline cleavage. Thus, a new synthetic method of methyl ketones $\left(\mathrm{RCH}_{2} \mathrm{COCH}_{3}\right)$ from alkyl halides (RX) has been established. The condensation of acetone with alkyl or alkenyl halide in liquid ammonia has been also described.
\end{abstract}

In the previous report ${ }^{11}$ it was described that alkyl halide condenses with mesityl oxide in liquid ammonia to afford in high yield a mixture of $a$-alkyl a-isopropenyl (III) and $a$-alkyl $a$-isopropylidene acetone (IV), of which (III) is main component.

In this paper the authors present the result by using dimethyl sulfoxide in place of liquid ammonia as solvent because the higher homologs of halide were less reactive in liquid ammonia and the yields of alkyl mesityl oxides were very poor.

Dimethyl sulfoxide has been used as solvent in the alkylation of malononitrile and 2,4pentanedione $^{2)}$ or the acylation of ketones ${ }^{3 \text { ) }}$ Corey and Chaykovsky ${ }^{4}$ have recently reported that sodium methyl sulfinyl carbanion $\left(\mathrm{CH}_{3} \mathrm{SOCH}_{2} \ominus \mathrm{Na}^{\oplus}\right)$ prepared from sodium hydride or amide with excess dimethyl sulfoxide is strongly basic and reacts with enolizable ketones affording preferentially by pro-

* Takasago Perfumery Co., Ltd., Tokyo.

1) M. Matsui, T. Yoshicla, and H. Mori, This Journal, 28, 95 (1964).

2) J.J. Bloomfield, J. Org. Chem., 26, 4112 (1961).

3) J.J. Bloomfield, ibid., 27, 2742 (1962).

4) E. J. Corey and M. Chaykovsky, J. Am. Chem. Soc., 84, 866 (1962). ton transfer enolates which are stable to further attack by the reagent.

Therefore, the combination of dimethyl sulfoxide as solvent and sodium sulfinyl carbanion as base was used in the alkylation of mesityl oxide with higher homologs of halide $\left(\mathrm{C}_{6}-\mathrm{C}_{10}\right)$, expecting to obtain in superior yields the products than those of in liquid ammonia.

In the case of tetrahydrogeranyl bromide the yield (the conjugated type (IV) was main product) was increased to $55 \sim 60 \%$ with dimethyl sulfinyl carbanion in dimethyl sulfoxide, but the yield was only about $30 \%$ in liquid ammonia. Some amounts of the dialkyl mesityl oxide and other side products, e.g., carbonyl addition product and methyl alkyl sulfoxicle $\left(\mathrm{CH}_{3} \mathrm{SOCH}_{2} \mathrm{R}\right)$ were also obtained though these were not further studied. Under similar way $n$-decyl, $n$-octyl, and $n$ hexyl mesityl oxides were obtained in 68.5, 63.4 , and $48.9 \%$ yields, respectively.

These condensed products were readily converted into methyl alkyl ketones by means of the two different courses of the cleavage; 
a) the end methylenic type product (III) is oxidized with ozone to $\beta$-diketone (XVII) which is cleaved into methyl alkyl ketone and acetic acid with alkali according to the usual procedure $^{5)}$, and b) both the end methylenic (III) and conjugated type product (IV) are stirred with acid such as sulfuric or a mixture of sulfuric and formic acids or sulfuric and acetic acids to yield methyl alkyl ketone and acetone.

For instance, the end methylenic type product of isoamyl mesityl oxides (IIIa) was oxidized with ozone to afford $\beta$-diketone (XVIIa) in about $70 \%$ yield which gave the characteristic purple enol test with ferric chloride and showed infrared absorption at 1702, $1727 \mathrm{~cm}^{-1} \quad(\mathrm{C}=\mathrm{O}$ of keto form) and $1605 \mathrm{~cm}^{-1} \quad(\mathrm{C}=\mathrm{O}$ of enol form), being identified with 3-isoamyl-2,4-pentadione by comparison of the infrared spectrum and the melting point of copper salt, m.p. $182 \sim 184^{\circ} \mathrm{C}$, with the authentic sample which was prepared by acetylation of methyl heptanone in the presence of boron trifluoride ${ }^{6)}$ or by heating sodium acetylacetone (XIX) and isoamyl iodide in a sealed tube ${ }^{7)}$ The $\beta$-diketone, on usual alkaline cleavage with diluted aqueous sodium hydroxide, gave methyl alkyl ketone, i.e., methyl heptanone (XVIIIa) (semicarbazone, m.p. $152 \sim 154^{\circ} \mathrm{C}$, 2,4-dinitrophenyl hy- drazone, m.p. $80 \sim 82^{\circ} \mathrm{C}$ ) in $89 \%$ yield and acetic acid. In this method, however, the conjugated type product (IV) could not be used as the intermediate of methyl alkyl ketone.

However, another simple way to get methyl alkyl ketone from alkyl mesityl oxide without hazardous ozonolysis has been found, where the condensed products (both the end methylenic and conjugated type products) are only treated with acid. On acidic treatment with $65 \%$ sulfuric acid, the end methylenic type product of isoamyl mesityl oxide (IIIa) was decomposed very rapidly to yield methyl heptanone (XVIIIa) (physical properties and derivatives are shown in Tables I \& II) and acetone (2,4-dinitrophenyl hydrazone, m.p. $\left.124.5 \sim 125.5^{\circ} \mathrm{C}\right)$. On the other hand the rate of acidic cleavage of the conjugated type product was much slower than that of the end methylenic type, but the same products, (XVIIIa) and acetone, were obtained.

In order to split off both the end methylenic and conjugated type products completely, the heating of alkyl mesityl oxides with a mixture of sulfuric and formic acids at $80 \sim 85^{\circ} \mathrm{C}$ for two hours was suitable in the case of the lower homologs than $n$-amyl or isoamyl mesityl oxide.

Although both types of alkyl mesityl oxides,

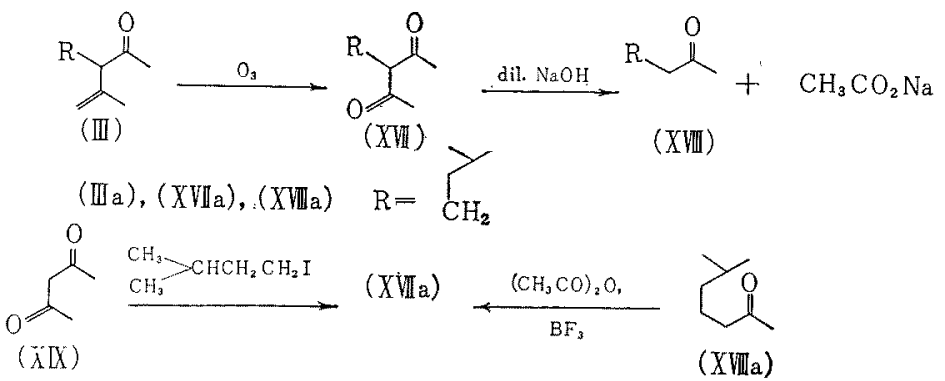

5) C.R. Hauser, F.W. Swamer and B.I. Ringler, J. Am. Chem. Soc, 70,4023 (1948)

6) R.M. Manyik et al., ibid., 75, 5030 (1953).

7) H. Adkins, W. Kuty and D.D. Cofman, ibid., 52, 3218 (1930).

especially the lower homologs, could be cleaved into methyl alkyl ketone and acetone by stirring with sulfuric acid only or sulfuric- 
TABle I. Yields AND PRoperties of Methyl AlKyl Ketones $\left(\mathrm{RCOCH}_{3}\right)$

\begin{tabular}{lccrcrrr}
\multicolumn{1}{c}{$\mathrm{R}$} & $\begin{array}{c}\text { Yieid**** } \\
(\%)\end{array}$ & $\begin{array}{c}\text { B.p. } \\
\left({ }^{\circ} \mathrm{C}\right)\end{array}$ & $\mathrm{mmHg}$ & $n_{\mathrm{D}}^{20}$ & $d_{4}^{20}$ & \multicolumn{2}{c}{$\mathrm{MR}_{\mathrm{D}}$} \\
$n$-butyl & 30.5 & $124 \sim 128$ & 760 & 1.4021 & 0.8126 & 30.02 & 29.92 \\
isoamyl & 38.6 & $51 \sim 53$ & 26 & 1.4082 & 0.8121 & 34.70 & 34.54 \\
$n$-amyl & 60.5 & $54 \sim 56$ & 23 & 1.4092 & 0.8150 & 34.65 & 34.54 \\
$n$-hexyl & 74.6 & $70 \sim 73$ & 23 & 1.4158 & 0.8174 & 39.35 & 39.16 \\
isohexyl* & 72.6 & $69 \sim 71$ & 27 & 1.4143 & 0.8108 & 39.54 & 39.16 \\
$n$-nonyl & 55.2 & $104 \sim 107$ & 6 & 1.4313 & 0.8316 & 53.04 & 53.01 \\
$n$-undecyl** & 51.0 & $124 \sim 126$ & 7 & - & - & - & - \\
H.P. I.*** & 42.4 & $106 \sim 111$ & 6 & 1.4350 & 0.8287 & 62.45 & 62.25 \\
$*$ Methyl heptanone. & $* *$ & Crystals. & F.P. $26^{\circ} \mathrm{C}$. & $* * *$ & Hexahydropseudoionone. & $* * * *$ & Based on sodium amide.
\end{tabular}

formic acids in yield of $80 \sim 90 \%$, the larger the molecular weight, the slower the rate of the mechanism of which is suggested as follows:

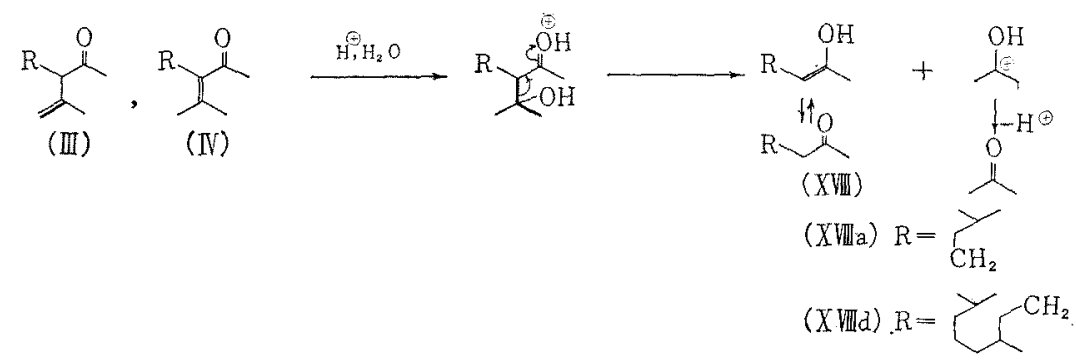

cleavage owing to the sparing solubility. Thus, it is very difficult to cleave tetrahydrogeranyl mesityl oxides, (IIId) and (IVd), with sulfuric acid only or sulfuric-formic acids, but by using a mixture of sulfuric and acetic acids at $80 \sim 85^{\circ} \mathrm{C}$ the cleavage completely finished after eight hours to afford hexahydropseudoionone (XVIIIId) in $85 \%$ yield and acetone.

According to this acid treatment, some alkyl methyl ketones including $n$-butyl, isoamyl, $n$ amyl, $n$-hexyl, isohexyl (methyl heptanone), n-nonyl, $n$-undecyl methyl ketones, and hexahydropseudoionone, were prepared from the corresponding alkyl mesityl oxides. The yields, physical properties and melting points of semicarbazones and 2,4-dinitrophenyl hydrazones of them are listed in Tables I \& II.

The acidic cleavage of alkyl mesityl oxides would be a kind of retrograde aldol reactions,
The difference of cleavage rate between (III) and (IV) with acid would be due to the difference of hydration rate to double bond at the first stage. Similarly pulegone ${ }^{83}$, piperitenone ${ }^{9)}$ and some other $\alpha, \beta$-unsaturated carbonyl compounds ${ }^{10}$ ) had been reported to be cleaved with acid or alkali in the earlier literatures.

Of the two methods mentioned above, the acidic cleavage procedure is generally better since it not only usually results in the best yields but also is considered simpler. However, the lower homologs of alkyl mesityl oxide, such as methyl, ethyl and propyl mesityl oxides, were not smoothly cleaved with acid, the reason was not investigated.

8) H. Rupe, $A n n_{2}, 459,206$ (1927).

9) Y.R. Naves, Helv. Chim. Acta, 25, 742 (1942)

10) V.I. Esafov, J. Gen. Chem. (U.S.S.R.), 9, 1841 (1939), C.A 34. $4053(1940)$; cf. C.A., 44, 9355 (1950), L. Kh. Freidlin and V.Z Sharf, C.A., 53, 4116 (1959). 
The present experiment has established a new, only two steps, synthetic method of methyl alkyl ketones via alkyl mesityl oxide in considerable yields; the over-all yield of methyl heptanone from isoamyl bromide and mesityl oxide, for example, is $72.6 \%$ based on sodium amide used.

An attempt to cleave isopentenyl mesityl oxide by acid hydrolysis failed owing to further side reactions. The authors have tried to condense alkyl or alkenyl halides with acetone directly under the same condition in liquid ammonia as described formerly, and found that isoamyl bromide, for example, condenses with acetone in the presence of sodium amide in liquid ammonia to give unfavorable disubstituted product, diisoamyl acetone $(\mathrm{XXa})$, in about $15 \%$ yield and isophorone $(\mathrm{XXI})$ in small amounts and expecting monosubstituted product, namely, methyl heptanone (XVIIIa) in an approximately equal amount. The first product was confirmed by the admixture with the authentic 2,4-dinitrophenyl hydrazone (m.p. $82 \sim 83^{\circ} \mathrm{C}$ ) prepared from tert-butyl acetoacetate via (XXII) and (XXIII), and the second and the third product (semicarbazone, m.p. 152 $154^{\circ} \mathrm{C}$ ) were confirmed by gas chromatography.

In ether instead of in liquid ammonia alkyl halide did not react with acetone but by selfcondensation of acetone itself isophorone, which showed infrared absorption at 1668 $(\mathrm{C}=\mathrm{O})$ and $1635 \mathrm{~cm}^{-1}(\mathrm{C}=\mathrm{C})$, ultraviolet peak at $236 \mathrm{~m}_{\mu} \quad(\epsilon=11800)$ and gave 2,4-dinitrophenyl hydrazone (m.p. $145 \sim 146^{\circ} \mathrm{C}$ ) as red flakes, was produced in moderate yield.

Similarly from isopentenyl chloride and acetone, methyl heptenone (XVIIIb) and diisopentenyl acetone $(\mathrm{XXb})$ were obtained in about 10 and $20 \%$ yields, respectively. Methyl heptenone obtained had b.p. $60 \sim 64^{\circ} \mathrm{C} / 12$ $\mathrm{mm}, \quad n_{\mathrm{D}}^{20} \quad 1.4403, d_{4}^{20} 0.8611, \mathrm{MR}_{\mathrm{D}} 38.64$ (Calcd. 38.69), showed infrared peak at 1715 $\mathrm{cm}^{-1}(\mathrm{C}=\mathrm{O})$, gave semicarbazone, m.p. 134 $136^{\circ} \mathrm{C}$ and 2,4-dinitrophenyl hydrazone, m.p. $88.5 \sim 89.5^{\circ} \mathrm{C}$, as orange long needles and was identical with authentic sample prepared from citral $^{11)}$, while the other novel component, diisopentenyl acetone, boiled at 116 $117^{\circ} \mathrm{C} / 11 \mathrm{~mm}$ as pale yellow liquid $\left(n_{\mathrm{D}}^{20}\right.$ 1.4642, $d_{4}^{20}$ 0.8729. MRD 61.45. Calcd. 61.35), showed infrared absorption at $1706 \mathrm{~cm}^{-1}$ $(\mathrm{C}=\mathrm{O})$, gave semicarbazone, m.p. $97 \sim 98^{\circ} \mathrm{C}$, as colorless needles and absorbed two moles of hydrogen to afford diisoamyl acetone (XXa).

Accordingly it was impossible to obtain the methyl alkyl ketone exclusively from alkyl halide and acetone.

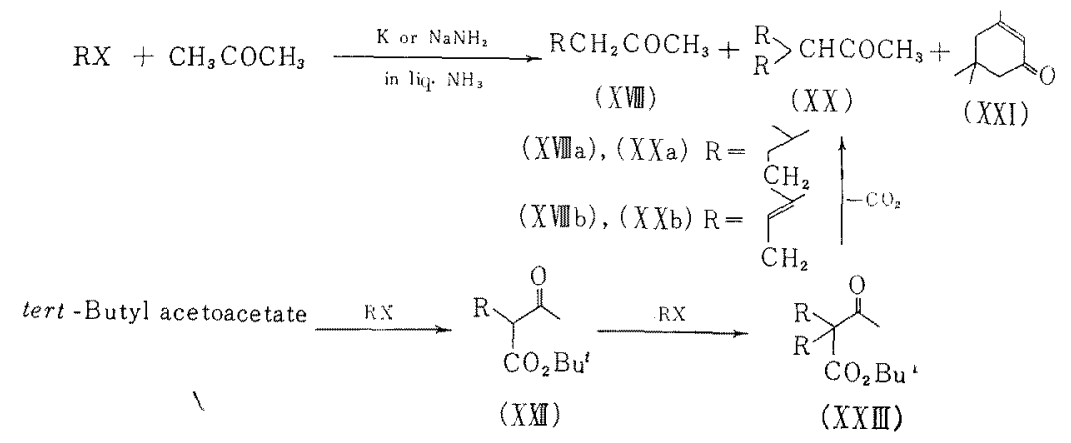

11) D.H. Hey and D.S. Morris, J. Chem. Soc., 1948, 48. 


\section{EXPERIMENTAL}

All melting and boiling points were uncorrected and solutions in organic solvents were dried over anhydrous sodium sulfate. Infrared spectra were measured in the state of liquid film.

\section{General Procedure for the Preparation of Methyl Alkyl Ketones.}

According to the procedure described in the preceding paper ${ }^{\mathrm{s}}$, the alkyl mesityl oxide was obtained from alkyl bromide and mesityl oxide with sodium amide in liquid ammonia in the case of alkyl $=\mathrm{C}_{3}-\mathrm{C}_{5}$ or in dimethyl sulfoxide in the case of alkyl $=\mathrm{C}_{\mathrm{B}}{ }^{-} \mathrm{C}_{10}$ (see below). After the distillation of unchanged bromide and mesityl oxide or lower boiling products through a Claisen flask or a Widmer column, the fraction, which was a mixture of end methylenic and conjugated type alkyl mesityl oxides, was treated with sulfuric-formic acid mixture (in the case of alkyl= $\mathrm{C}_{3}-\mathrm{C}_{3}$ ) or sulfuric-acetic acid mixture (in the case of alkyl $=\mathrm{C}_{\mathrm{B}} \cdot \mathrm{C}_{10}$ ) in the manner described below to yield methyl alkyl ketone. The methyl alkyl ketones obtained were identified by infrared spectrum, MRD, semicarbazone, and 2,4-dinitrophenyl hydrazone (2,4DNP)). The yields based on sodium amide, physical properties and derivatives of some methyl ketones are listed in Tables I \& II.

\section{Acidic Cleavage of Alkyl Mesityl Oxide.}

a) With Sulfuric-formic Acid Mixture. A mixture of $65 \%$ sulfuric acid $(60 \mathrm{~g}, 0.4 \mathrm{~mol})$ and commercial $85 \%$ formic acid $(54 \mathrm{~g}, 1.0 \mathrm{~mol})$ was heated at $80 \sim$ $85^{\circ} \mathrm{C}$. To this mixture was added alkyl mesityl oxide (0.1 mol) (alkyl groups with less carbon chain than
$\mathrm{C}_{\bar{b}}$, and the mixture stirred for $2 \mathrm{hr}$. at this temperature. After cooling and the addition of saturated sodium chloride solution $(50 \sim 60 \mathrm{ml})$, the oily layer was separated and then the ether extract was combined, washed with aqueous sodium chloride, $5 \%$ sodium carbonate solution, and water successively, and dried. After the removal of ether, the liquid was distilled to give methyl alkyl ketone in $72 \sim 90 \%$ yield.

Under this condition methyl heptanone $(10.5 \mathrm{~g}$, $82 \%$ ) was obtained from isoamyl mesityl oxide ( $16.8 \mathrm{~g}$, $0.1 \mathrm{~mol})$ which was composed of the end methylenic $60 \%$ and the conjugated type product $40 \%$. b.p. $50 \sim$ $55^{\circ} \mathrm{C} / 10 \mathrm{~mm}$, the physical properties and the deriva. tives of which are given in Tables I \& II. To the water layer extracted with ether was added 2,4-dinitrophenyl hydrazin hydrochloride in ethanol to afford acetone 2,4-DNP, m.p., $124.5 \sim 125.5^{\circ} \mathrm{C}$, as yellow needles from ethanol, undepressed by admixture with an authentic sample.

b) With Sulfuric-acetic Acid Mixture. To a mixture of $65 \%$ sulfuric acid $(60 \mathrm{~g})$ and acetic acid $(60 \mathrm{~g})$ was added alkyl mesityl oxide $(0.1 \mathrm{~mol}$ ) (alkyl groups with more carbon chain than $\mathrm{C}_{6}$ ), and stirred for $8 \mathrm{hr}$. at $80 \sim 85^{\circ} \mathrm{C}$. By the same treatment mentioned above methyl alkyl ketone was obtained in $80 \sim 90 \%$ yield.

From tetrahydrogeranyl mesityl oxides (23.8 g), which consisted of the end methylenic $55 \%$ and the conjugated type product $45 \%$, hexahydropseudoionone (XVIIId) $\quad(17.0 \mathrm{~g}, 85.8 \%)$ was obtained, b.p. 106 $111^{\circ} \mathrm{C} / 6 \mathrm{~mm}$, the physical properties and the derivatives of which are given in Tables $I$ \& II.

Table II. Derivatives of Methyl Alkyl Ketones $\left(\mathrm{RCOCH}_{3}\right)$.

\begin{tabular}{|c|c|c|c|c|}
\hline \multirow[b]{2}{*}{$\mathrm{R}$} & \multicolumn{2}{|c|}{$\begin{array}{c}\text { M.p. of } \\
\text { semicarbazone }\left({ }^{\circ} \mathrm{C}\right)\end{array}$} & \multicolumn{2}{|c|}{$\begin{array}{c}\text { M.p. of } \\
\text { 2,4-dinitrophenyl hydrazone }\left({ }^{\circ} \mathrm{G}\right)\end{array}$} \\
\hline & Found & Reported & Found & Reported \\
\hline$n$-butyl & $124.5 \sim 125.5$ & $125^{a)}$ & $107.0 \sim 108.5$ & $108^{a}$ \\
\hline isoamyl & $144 \sim 146$ & $146 \sim 147 b)$ & $95 \sim 97$ & $94 \sim 96$ ) \\
\hline$n$-amyl & $123 \sim 125$ & $\left.123 \sim 124^{c}\right)$ & $73.0 \sim 74.5$ & $\left.73.0 \sim 74.5^{a}\right)$ \\
\hline$n$-hexyl & $123.5 \sim 124.5$ & $123^{a}$ & $59 \sim 60$ & $59.5^{(1)}$ \\
\hline isohexyl* & $152 \sim 154$ & $154 \sim 155^{d)}$ & $79.0 \sim 80.5$ & $\left.77^{d}\right)$ \\
\hline n-nonyl & $122 \sim 123$ & $123 \sim 124^{a}$ & $64.5 \sim 66.0$ & $\left.64 \sim 65^{a}\right)$ \\
\hline$n$-undecyl & $123.5 \sim 124.5$ & $124.5^{2}$ & $71.0 \sim 72.5$ & $72^{a}$ \\
\hline H.P.I.** & $98 \sim 99$ & $97 \sim 98 \mathrm{e}$ & $38.5 \sim 39.5$ & $36 \sim 37 \mu)$ \\
\hline
\end{tabular}

* Methyl heptanone. ** Hexahydropseudoionone.

a) T. Shenton and J.C. Smith, Chem, and. Ind. (London), 1958, 1510. b) H.S. Rhinesmith, J. Am. Chem. Soc., 58, 596 (1936). c) D.Y. Curtin et al., J. Org. Chem., 24, 97 (1959). d) D.H. Hey and D.S. Morris, J. Chem. Soc., 1948, 48. e) I.M. Heilbron and A. Thompson, ibid, 1929, 888. f) R.C. Huston and C.O. Bostwick, J. Org. Chem., 13, 331 (1948), C.A. 42, 5842 (1948). g) I.K. Sarycheva et al, C.A., 54, 1457 (1960). 


\section{Condensation of Mesityl Oxide with Alkyl Halide in Dimethyl Sulfoxide.}

According to the directions of Corey", commercial sodium amide $(3.9 \mathrm{~g}, 0.1 \mathrm{~mol})$ in dimethyl sulfoxide $(100 \mathrm{ml})$ was stirred at $65 \sim 70^{\circ} \mathrm{C}$ for about $30 \mathrm{~min}$ under nitrogen until evolution of ammonia was complete. After cooling below $20^{\circ} \mathrm{C}$ to this mixture was added dropwise mesityl oxide $(11.8 \mathrm{~g}, 0.12 \mathrm{~mol})$ in dimethyl sulfoxide $(20 \mathrm{ml})$ during $5 \sim 10 \mathrm{~min}$. with stirring at the temperature of just above freezing point. To the mixture which had been further stirred for $10 \mathrm{~min}$. at this temperature was added tetrahydrogeranyl bromide $(22.1 \mathrm{~g}, 0.1 \mathrm{~mol})$ over a period of $20 \mathrm{~min}$, below $20^{\circ} \mathrm{C}$. The mixture was further stirred for $2 \mathrm{hr}$. at room temperature and water $(150 \sim 200$ ml) was added. The mixture was then extracted with petroleum ether three times, washed with water, $5 \%$ hydrochloric acid and water successively and dried. After the removal of solvent the residue was distilled under reduced pressure to yield tetrahydrogeranyl mesityl oxide which was composed of the end methylenic type product, $20 \%$, and the conjugated type one, $80 \%$, b.p. $120 \sim 140^{\circ} \mathrm{C} / 6 \mathrm{~mm}, 13.1 \sim 14.3 \mathrm{~g} \quad(55 \sim 60 \%)$. Under similar way $n$-decyl (b.p. $120 \sim 150^{\circ} \mathrm{C} / 6 \mathrm{~mm}$ ), $n$-octyl (b.p. $106 \sim 126^{\circ} \mathrm{C} / 8 \mathrm{~mm}$ ), and $n$-hexyl (b.p. $80 \sim 103^{\circ} \mathrm{C} / 8 \mathrm{~mm}$ ) mesityl oxide were obtained in 68.5 , 63.4 , and $48.9 \%$ yields, respectively, but the yield of isoamyl mesityl oxide was only $53.4 \% \quad(86.8 \%$ in liquid ammonia) may be because of side reactions.

Although with the combination of dimethyl sulfoxide and powdered sodium methoxide was obtained the condensed product in yield inferior to that of mentioned above, other combinations, dimethyl form. amide and sodium amide or tert-butanol and potassium tert-butoxide, were not effective.

Ozonolysis of 3-Isoamyl-4-methyl-4-penten-2-one (IIIa).

The ketone (IIIa, ca. 90\% content) (5l g) in carbon tetrachloride $(400 \mathrm{ml})$ was treated with ozone at $0 \sim 5^{\circ} \mathrm{C}$ as long as ozone was completely absorbed. The mixture was added dropwise to $18 \%$ aqueous sodium bisulfite $(200 \mathrm{~g})$ with stirring. As much heat was cvolved, the reaction mixture was kept below $45 \sim 50^{\circ} \mathrm{C}$ on a water-bath. After the addition, the mixture was stirred for $1 \mathrm{hr}$. Then $15 \%$ sulfuric acid $(100 \mathrm{~g})$ was added to the mixture in small portions, and the whole stirred further for $1 \mathrm{hr}$. The organic layer was separated and washed with water and the solvent after drying was distilled off and the residue distilled under reduced pressure to give 3-isoamyl- 2,4-pentadione (XVIIa) $(35.8 \mathrm{~g}, 69.8 \%)$, b.p. 60 $80^{\circ} \mathrm{C} / 2 \sim 3 \mathrm{~mm}$. It gave the purple enol test with fcrric chloride and copper salt, m.p. $182 \sim 184^{\circ} \mathrm{C}$ as white grey needles from methanol, which was identical with the authentic sample synthesized from methyl heptanone or acetylacetone as described later.

The copper salt $(16.3 \mathrm{~g})$ was stirred with $10 \%$ sulfuric acid $(100 \mathrm{ml})$ and ether $(100 \mathrm{ml})$ to regenerate pure 3-isoamyl-2,4-pentadione (XVIIa) $(9.7 \mathrm{~g}$ ), b.p. $89 \sim 90^{\circ} \mathrm{C} / 6 \mathrm{~mm}, n_{\mathrm{D}}^{20} 1.4531, d_{4}^{20} 0.9202, d_{20}^{20} 0.9218$. Anal. Found: C, 69.91; H, 10.50. Calcd. for $\mathrm{C}_{10} \mathrm{H}_{18} \mathrm{O}_{2}$ : $\mathrm{C}, 70.54 ; \mathrm{H}, 10.66 \%$. It showed infrared absorption at 1702,1727 (CO-CH-CO) and $1605 \mathrm{~cm}^{-1}(\mathrm{COH}=$ C-CO).

Alkaline Cleavage of 3-Isoamyl-2,4-pentadione (XVIIa). The $\beta$-diketone (XVIIa) (5.1 g, $0.03 \mathrm{~mol})$ was dis. solved in $5 \%$ sodium hydroxide solution $(30 \mathrm{ml})$ and the resulting solution refluxed with stirring for $2 \mathrm{hr}$., cooled and extracted with ether. The ether extract was dried and after the removal of ether the residue was distilled to give methyl heptanone (XVIIIa) (3.4 g, $88.5 \%$ ), b.p. $62 \sim 64^{\circ} \mathrm{C} / 17 \mathrm{~mm}$, colorless liquid having amyl acetate-like odor, $n_{\mathrm{D}}^{20} 1.4148, d_{4}^{20} 0.8160, d_{20}^{20}$ 0.8174 . I.R. spectrum was identical with the authen* tic one. It gave semicarbazone, m.p. $152 \sim 154^{\circ} \mathrm{C}$, as colorless scaly crystals from ethanol (lit. 154 $\left.155^{\circ} \mathrm{C}\right)^{113}$. Anal. Found: C, 58.65; H, $10.82 ; \mathrm{N}, 22.13$. Calcd. for $\mathrm{C}_{9} \mathrm{H}_{19} \mathrm{ON}_{3}: \mathrm{C}, 58.34 ; \mathrm{H}, 10.34 ; \mathrm{N}, 22.68 \%$. Conversion into the 2,4-DNP and recrystallization from ethanol gave a derivative, m.p. $80 \sim 82^{\circ} \mathrm{C}$, as yellowish orange fine needles (lit. $77^{\circ} \mathrm{C}$ ) ${ }^{11)}$. Anal. Found: $\mathrm{C}, 54.78 ; \mathrm{H}, 6.61 ; \mathrm{N}, 18.21$. Calcd. for $\mathrm{C}_{14} \mathrm{H}_{20} \mathrm{O}_{4} \mathrm{~N}_{1}:$ C. $54.53 ; \mathrm{H}, 6.54 ; \mathrm{N}, 18.17 \%$. Authentic synthetic methyl heptanonei1) gave the derivatives of the same m.p., undepressed on admixtures.

\section{Preparation of 3-Isoamyl-2,4-pentadion (XVIIa).}

a) From Methyl Heptanone. In the modified procedure of Manyik $^{\theta)}$, to commercial boron trifluoride diacetate $(50 \mathrm{~g}, 0.27 \mathrm{~mol})$ were rapidly added methyl heptanone $\mathrm{e}^{11)}(10.3 \mathrm{~g}, 0.08 \mathrm{~mol})$ and acetic anhydride $(16.3 \mathrm{~g}, 0.16 \mathrm{~mol})$ as a mixture or separately with icebath cooling, and stirring for $30 \mathrm{~min}$; then the icebath was removed and the mixture was stirred for $4 \mathrm{hr}$. at room temperature and further for $30 \mathrm{~min}$. on a boiing water-bath. The mixture was cooled to room temperature, poured into a solution of sodium acetate $(26.2 \mathrm{~g})$ in water $(150 \mathrm{ml})$, refluxed for $1 \mathrm{hr}$., chilled and extracted with petroleum ether. The extract was 
washed with water, dried and distilled to give the crude $\beta$-diketone $(7.5 \mathrm{~g}, 55 \%)$, contaminated with methyl derivative, b.p. $81^{\circ} \mathrm{C} / 4 \mathrm{~mm}$. In order to remove methyl derivative the acetylation product $(20 \mathrm{~g})$ was treated with cold $1 \%$ aqueous sodium hydroxide according to the directions of Hauser ${ }^{12)}$ to yield pure 3-isoamyl-2,4-pentadione (XVIIa), b.p. $80 \sim 82^{\circ} \mathrm{C} / 3$ $\mathrm{mm}, 8.9 \mathrm{~g}, n_{\mathrm{D}}^{20} 1.4457, d_{4}^{20} 0.9108, d_{20}^{20} 0.9124$, which gave the purple enol test with ferric chloride and copper salt, m.p. $182 \sim 184^{\circ} \mathrm{C}$, as grey fine needles from methanol

b) Form Acetylacetone." Acetylacetone (XIX) $(25 \mathrm{~g})$ in dry ether $(250 \mathrm{ml})$ was added dropwise to powdered sodium $(5.5 \mathrm{~g})$ suspended in dry ether $(75$ ml) with stirring. After the evolution of heat had ceased, the mixture was refluxed for $24 \mathrm{hr}$. The white sodium salt precipitated was filtered and dried over potassium hydroxide in a vacuum desiccator (yield, $34 \mathrm{~g}$ ). In an autoclave was added acetylacetone sodium salt $(12.2 \mathrm{~g}, 0.1 \mathrm{~mol})$ and isoamyl iodide $(79.2 \mathrm{~g}, 0.4 \mathrm{~mol})$. The mixture was heated at $180 \sim$ $190^{\circ} \mathrm{C}$ for $4 \mathrm{hr}$. After cooling the mixture was poured into water and extracted with ether. The ether extract was washed with water, dried and distilled to give 3-isoamyl-2,4-pentadione (XVIIa) (4.6 g, 27\%), b.p. $75 \sim 76^{\circ} \mathrm{C} / 3 \mathrm{~mm}$, colorless liquid, $n_{\mathrm{D}}^{20} 1.4491, d_{4}^{20}$ $0.9135, d_{20}^{20} 0.9151$, copper salt, m.p. $182 \sim 184^{\circ} \mathrm{C}$, which was identical with the sample synthesized from methyl heptanone.

I.R. spectra and other data of the two $\beta$-diketones prepared above were completely identical with that of the specimen derived from 3-isoamyl-4-methyl-4penten-2-one (IIIa).

\section{Condensation of Acetone with Isoamyl Bromide and Isopentenyl Chloride.}

a) With Isoamyl Bromide in Liquid Ammonia.

Potassium amide was prepared from potassium metal $(7.8 \mathrm{~g}, 0.2 \mathrm{~mol})$ and liquid ammonia $(300 \mathrm{ml})$ as described in the experiment with mesityl oxide (sce the foregoing paper). To the solution was added acetone $(23.2 \mathrm{~g}, 0.4 \mathrm{~mol})$ with stirring and the mixture was stirred for $10 \mathrm{~min}$. in an acetone-dry-ice bath. Isoamyl bromide $(30.2 \mathrm{~g}, 0.2 \mathrm{~mol})$ was then added dropwise during $20 \mathrm{~min}$. The mixture was stirred for $1 \mathrm{hr}$. in a cooling bath, then for $1 \mathrm{hr}$. at room temperature and allowed to stand overnight to effect evaporation of ammonia. The residue was dissolved

12) C.R. Hauser and J.T. Adams, $J$. Am. Chem. Soc., 66, 345 (1944). in ice-water cautiously, and extracted with ether. The extract was washed with water, $5 \%$ hydrochloric acid, and water successively and then distilled into four fractions as follows: 1) b.p. $-60^{\circ} \mathrm{C} / 17 \mathrm{~mm}, 5.2 \mathrm{~g}$, $n_{\mathrm{D}}^{20} 1.4300, d_{4}^{20} 0.9954$, a mixture of unaltered bromide and methyl heptanone; 2) b.p. $60 \sim 80^{\circ} \mathrm{C} / 17 \mathrm{~mm}, 4.1 \mathrm{~g}$ $(16 \%), \quad n_{\mathrm{D}}^{20} 1.4223, d_{4}^{20} 0.8324$, semicarbazone, m.p. $152 \sim 154^{\circ} \mathrm{C}$. It was in accordance with methyl heptanone (XVIIIa); 3) b.p. $80 \sim 115^{\circ} \mathrm{C} / 15 \mathrm{~mm}, 5.6 \mathrm{~g}$ $(14.1 \%), n_{\mathrm{D}}^{20} 1.4399, d_{4}^{20} 0.8566,2,4-\mathrm{DNP}, \mathrm{m} . \mathrm{p} .82 \sim$ $83^{\circ} \mathrm{C}$, as yellow long needles from ethanol. Anal. Found: $\mathrm{C}, 60.78 ; \mathrm{H}, 8.07 ; \mathrm{N}$, 14.91. Calcd. for $\mathrm{C}_{10} \mathrm{H}_{30} \mathrm{O}_{4} \mathrm{~N}_{1} ; \quad \mathrm{C}, 60.29 ; \mathrm{H}, 7.99 ; \mathrm{N}, 14.81 \%$. Synthetic diisoamyl acetone (XXa) described below gave 2,4DNP of the same m.p., undepressed on admixture; 4) Residue of distillation, $4.7 \mathrm{~g}$. In fraction 3) and 4) was detectable a small amount of isophorone (XXI) by gas chromatography.

b) With Isoamyl Bromide in Ether. In a similar way sodium or potassium amide $(0.2 \mathrm{~mol})$ was prepared. When the reaction was complete, the ammonia was allowed to evaporate on a water-bath at $30 \sim 35^{\circ} \mathrm{C}$ gently. When little ammonia remained, dry ether $(300 \mathrm{ml})$ was added and sodium or potassium amide stirred into suspension. The suspension was refuxed until no ammonia remained. To the suspension was added a mixture of acetone $(12.8 \mathrm{~g}, 0.22 \mathrm{~mol}$ ) and isoamyl bromide $(30.2 \mathrm{~g}, 0.2 \mathrm{~mol})$ during $30 \mathrm{~min}$. at $15^{\circ} \mathrm{C}$. The mixture was stirred for $1 \mathrm{hr}$. at room temperature and refluxed for $2 \mathrm{hr}$. After the addition of methanol and water, the ether layer was separated. washed with water, $5 \%$ sodium carbonate, water, $5 \%$ hydrochloric acid, and water successively and dried. On distillation of the ether solution, besides unaltered bromide $(21.8 \mathrm{~g})$, isophorone (XXI) was obtained, b.p. $95 \sim 100^{\circ} \mathrm{C} / 15 \mathrm{~mm}, 2.9 \mathrm{~g}, n_{\mathrm{D}}^{20} 1.4797, d_{4}^{20} 0.9242$, $d_{20}^{20} 0.9258$, $\nu_{\max }: 1668(\mathrm{C}=\mathrm{O}), 1635$ and $820 \mathrm{~cm}^{-1}$ $(>\mathrm{C}=\mathrm{CH}-), \quad \lambda_{\max }^{\mathrm{EtOH}} \quad 236 \mathrm{~m}_{\mu} \quad(\epsilon=11800, \log \epsilon 4.07)$, 2,4-DNP, m.p. $145 \sim 146^{\circ} \mathrm{C}$ (melted at $153^{\circ} \mathrm{C}$ completely) as red flakes from ethanol (lit. $146^{\circ} \mathrm{C}$ ) ${ }^{13}$. Anal. Found: C, 56.82; H, 5.64; N, 17.35. Calcd. for $\mathrm{C}_{15} \mathrm{H}_{15} \mathrm{O}_{4} \mathrm{~N}_{4}: \mathrm{C}, 56.59 ; \mathrm{H}, 5.70 ; \mathrm{N}, 17.60 \%$. Mixed m.p. with authentic isophotone 2,4-DNP (m.p. $145 \sim 146^{\circ} \mathrm{C}$ ) showed no depression.

c) With Isopentenyl Chloride. In a similar way from acetone $(34.8 \mathrm{~g}, 0.6 \mathrm{~mol})$, isopentenyl chloride ${ }^{24}$

13) E.A. Braude and E.A. Evans, J. Chem. Soc., 1954, 611.

14) J.A. Kemp and Co., Brit. Patent, 851, 658 (1960). 


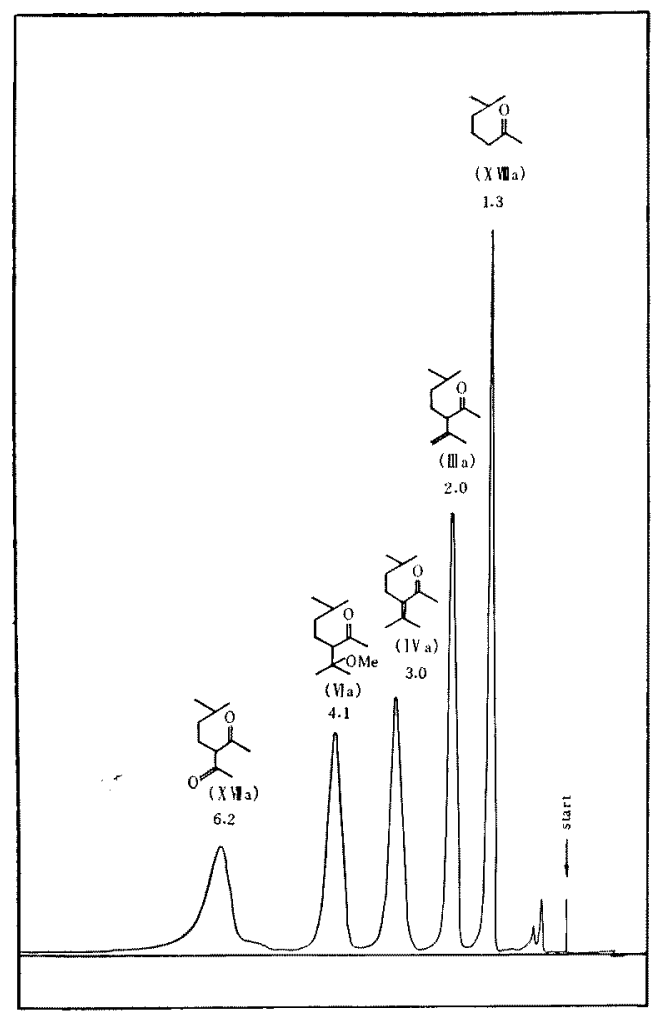

FIG. 1. Gas Chromatogram of (IIIa), (IVa), (VIa), (XVIIa), and (XVIIIa) at $150^{\circ} \mathrm{C}$.

(The figures under the formula refresent retention times in min.)

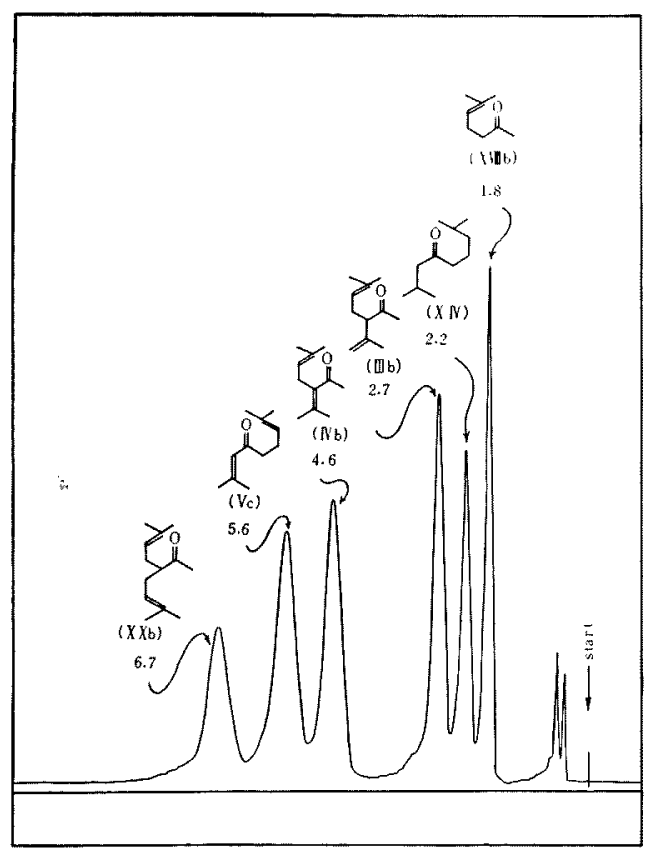

FIG. 2. Gas Chromatogram of (IIIb), (IVb), (Vc), (XIV), (XVIIIb), and (XXb) at $150^{\circ} \mathrm{C}$.

(The figures under the formula represent retention times in min.)

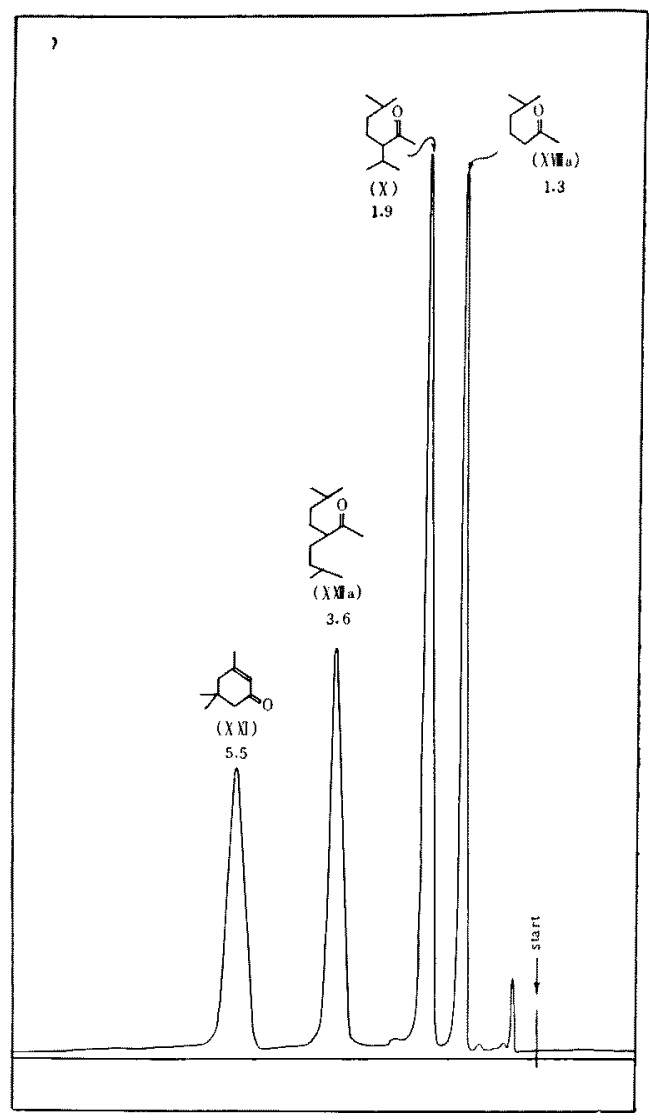

FIG. 3. Gas Chromatogram of (X), (XVIIIa), (XXI), and (XXIIa) at $150^{\circ} \mathrm{C}$.

(The figures under the lormula represent retention times in min.)

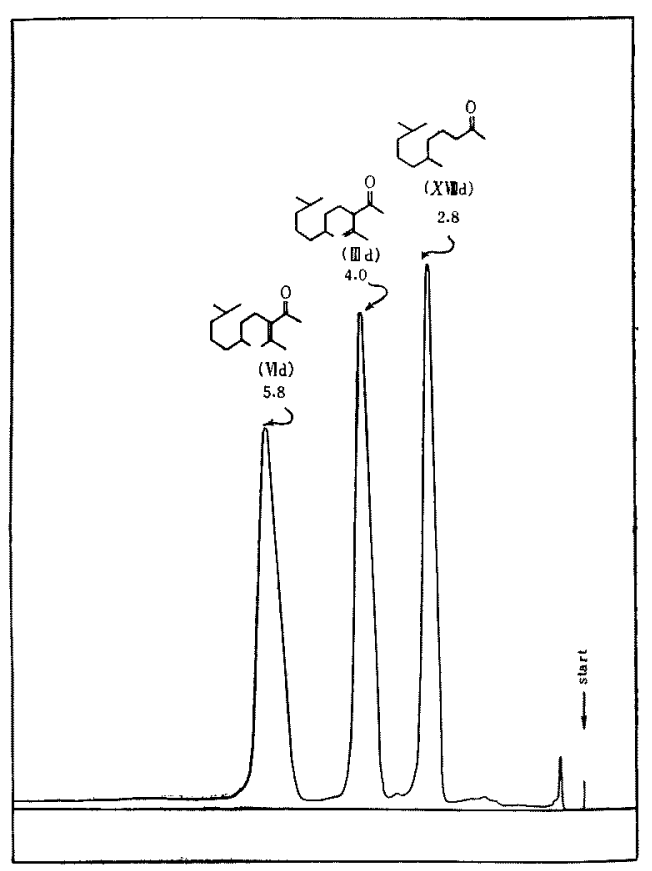

FIG. 4. Gas Chromatogram of (IIId), (IVd), and (XVIIId) at $180^{\circ} \mathrm{C}$.

(The figures under the formula represent retention times in min.) 
(25 $\mathrm{g}, 0.24 \mathrm{~mol})$ and sodium $(4.6 \mathrm{~g}, 0.2 \mathrm{~mol})$ in liquid ammonia $(250 \mathrm{ml})$ was obtained the condensed prod. uct which consisted of methyl heptenone (XVIIIb), $36.6 \%$, and disopentenyl acetone (XXb), 63.4\%, by gas chromatographic analysis. The condensed product was distilled under reduced pressure to give the two components, namely, the lower boiling fraction, b.p. $58 \sim 78^{\circ} \mathrm{C} / 10 \mathrm{~mm}, 2.7 \mathrm{~g}(10.7 \%)$ and the higher boiling one, b.p. $110 \sim 123^{\circ} \mathrm{C} / 10 \mathrm{~mm}, 8.1 \mathrm{~g} \quad(20.8 \%)$.

The former was redistilled to afford pure methyl heptenone, b.p. $\quad 60 \sim 64^{\circ} \mathrm{C} / 12 \mathrm{~mm}, \quad n_{\mathrm{D}}^{20}$ 1.4403, $d_{4}^{20}$ $0.8611, d_{20}^{20} 0.8626, \mathrm{MR}_{\mathrm{D}} 38.64$ (Calcd. 38.69), $\nu_{\max }$ : $1715 \mathrm{~cm}^{-1}(\mathrm{C}=\mathrm{O})$. It gave semicarbazone, m.p. 134 $136^{\circ} \mathrm{C}$, as needles from ethanol-water (lit. $135 \sim$ $\left.136^{\circ} \mathrm{C}\right)^{\mathrm{w})}$. Anal. Found: C, 58.93; H, 9.45; N, 23.23. Calcd. for $\mathrm{C}_{4} \mathrm{H}_{37} \mathrm{ON}_{3} ; \mathrm{C}, 58.98 ; \mathrm{H}, 9.35 ; \mathrm{N}, 22.93 \%$. It gave 2,4-DNP, m.p. $88.5 \sim 89.5^{\circ} \mathrm{C}$, as orange long needles from ethanol (lit. $78 \sim 80^{15)}, 81^{13)}, 88^{15)}$, $85.5 \sim 86.0^{\circ} \mathrm{C}^{18)}$ ). Anal. Found: C, $54.74 ; \mathrm{H}, 6.28 ; \mathrm{N}$, 18.39. Calcd. for $\mathrm{C}_{14} \mathrm{H}_{18} \mathrm{O}_{4} \mathrm{~N}_{4}: \mathrm{C}, 54.89 ; \mathrm{H}, 5.92 ; \mathrm{N}$, $18.29 \%$. No depression of m.p. occurred on admixture of the two derivatives with the authentic samples derived from methyl heptenone ${ }^{11)}$.

The higher boiling fraction was redistilled to give pure unknown disopentenyl acetone $(\mathrm{XXb})$, b.p. 115 $118^{\circ} \mathrm{C} / 11 \mathrm{~mm}$, pale yellow liquid, $n_{\mathrm{D}}^{20} 1.4642, d_{4}^{20} 0.8729$, $d_{20}^{20} 0.8745, \mathrm{MR}_{\mathrm{D}} 61.45$ (CaIcd. 61.35 ), $\nu_{\text {max }}: 1706 \mathrm{~cm}^{-1}$ $\left(\mathrm{C}=\mathrm{O}\right.$ ), semicarbazone, m.p. $97 \sim 98^{\circ} \mathrm{C}$, as needles from ethanol-water. Anal. Found: C, $66.77 ; \mathrm{H}, 10.21 ; \mathrm{N}$, 16.92. Calcd. for $\mathrm{C}_{71} \mathrm{H}_{23} \mathrm{ON}_{3}: \mathrm{C}, 66.89 ; \mathrm{H}, 10.03 ; \mathrm{N}$,

\footnotetext{
15) M. Julia, S. Julia et R. Guégan, Bull. Soc. Chim. Frante, 1960 , 1076.

16) H. Normant and C. Feugeas, Compt. rend., 248, 425 (1959).

17) I.N. Nazarov, L.A. Kazitsyna, and I.I. Zaretskaya, C.A., 51 16383 (1957).

18) 1.N. Nazarov et al, C.A., 52, 247 (1958): cf. T. Leda, Koryo, No. 50, $45(1958)$.
}

$16.72 \%$

The disopentenyl acetone in $n$-hexane was hydrogenated in the presence of Raney nickel to give diisoamyl acetone $(\mathrm{XXa})$ which was identified by comparison of I.R. spectrum and gas chromatography.

\section{Preparation of Diisoamyl Acetone (XXa).}

In a similar manner described in the preparation of 3-isoamyl-4-methyl-2-pentanone $(\mathrm{X})^{13}$, tert-butyl a,a-diisoamylacetoacetate (XXIII) $(23 \mathrm{~g})$, which was prepared from tert-butyl a-isoamyl acetoacetate (XXII) $(22.8 \mathrm{~g}, 0.1 \mathrm{~mol})$ and isoamyl bromide $(18.1 \mathrm{~g}, 0.12$ mol) in $85.7 \%$ yield, was heated with p-toluenesulfonic acid $(1.2 \mathrm{~g})$ to afford diisoamyl acetone (XXa) (12.8 g, $80.1 \%$ ), b.p. $108 \sim 112^{\circ} \mathrm{C} / 13 \mathrm{~mm}, \quad n_{\mathrm{D}}^{20} 1.4323, d_{4}^{20}$ $0.8247, d_{20}^{20} 0.8262, \mathrm{MR}_{\mathrm{D}} 62.12$ (Calcd. 62.25), 2,4-DNP, m.p. $82 \sim 83^{\circ} \mathrm{C}$, as yellow long needles from ethanol.

\section{Gas Chromatography.}

The samples were introduced through a $200 \times 0.32 \mathrm{~cm}$ i.d. stainless steel column packed with $10 \mathrm{wt} \%$ Reoplex on celite $545(50 \sim 80 \mathrm{mesh})$ at $150^{\circ} \mathrm{C}$ or $180^{\circ} \mathrm{C}, 50 \sim$ $55 \mathrm{ml}$ of helium per min. as carrier gas, 1.02 or $1.09 \mathrm{~kg} / \mathrm{cm}^{2}$ inlet pressure. The retention times of cis- and trans-4,8-dimethyl-3,7-nonadien-2-one (XIII) were 4.8 and $6.0 \mathrm{~min}$, respectively at $150^{\circ} \mathrm{C}$. Gas chromatogram and retention times of other compounds are given in Figs. $1 \sim 4$.

Acknowledgment. The authors are indebted to Mr. K. Aizawa for measurements of infrared spectra and to the members of the Analytical Laboratory of the Department of Agricultural Chemistry, the University of Tokyo, for microanalytical data. 